significant $(\mathrm{p}=0.45)$. As expected, the arterial calcium load, corresponding to the extent of vessel calcification, was higher in patients treated with statins (14 [range $2-35$ ] vs. 8 [range $0-35$ ]; $p=0.012$ ). However, calcium load did not correlate with the TVS, whereas it inversely correlated with SUVs $(p=0.03)$. At multiple regression, assumption of statins was not predicted by sex, type of diagnosis, GC treatment or presence of LVV at PET/CT. Only age predicted statin therapy $(p=0.04)$, but age was not associated with LVV $(p=0.23)$. Among clinical features, only fever was significantly less frequent in patients treated with statins $(p=0.03)$.

Conclusions: With the limits of an observational retrospective study, our data suggest that treatment with statins may lower arterial uptake in patients studied for LVV. This finding was seen using the theoretically more subjective TVS but not with SUV analysis. We feel that the latter is more easily influenced by the presence of calcific plaques, as suggested by its inverse correlation with arterial calcium load. The role of statins in tempering arterial inflammation deserves further studies.

Disclosure of Interest: None declared

DOI: 10.1136/annrheumdis-2018-eular.7129

\section{AB0684 A REVIEW OF TEMPORAL ARTERY BIOPSIES AT A DISTRICT GENERAL HOSPITAL}

M.A. Yusuf, M. Al-Zaza, T. Walton. Colchester Hospital University NHS Trust, Colchester, UK

Background: Giant cell arteritis is the most common vasculitis in the western world in the over 50 population. The morbidity associated with its natural progression and treatment is significant. No single investigation has been identified to accurately confirm or reject its diagnosis, though for some years biopsy of the superficial temporal artery has been carried out to support the diagnostic process. More recently, doppler ultrasound of the artery has gained prominence, though its widespread use is limited.

Temporal artery biopsy (TAB) is a significant use of resources, involving a surgeon and their team, as well as a histopathologist. It is an invasive procedure with the risks that this entails. It behoves the referring doctor to ensure that the probability of a positive result is as high as practicable.

Objectives: To determine the factors providing the highest likelihood of a positive TAB result.

Methods: The notes of all patients undergoing a TAB during a 3 year period 2013-2016 were requested from the Medical Records department at a district general hospital. The first 100 of these were reviewed by the authors. Each set of notes was examined for the following:

- Demographics (sex, age)

- The first department the patient was referred to (Rheumatology/Ophthalmology/ Neurology/direct from the General Practitioner to Vascular Surgery)

Period of time from symptom onset to biopsy

- Period of time on steroids to biopsy

- Initial dose of steroids prescribed

- Pre-treatment ESR

- Pre-treatment CRP

- Presence of symptoms (headache/jaw claudication/polymyalgia rheumatica)

- Other causes for a raised ESR

- The pre-test probability of a positive TAB result as assessed by the reviewer

- TAB result as reported by local histopathologist

- Evidence of the biopsy result impacting treatment

Results: Of the 100 TAB's reviewed, 16 yielded positive results (16\%). A breakdown of the notes review for these patients is included in the following table:

Abstract AB0684 - Table 1

\begin{tabular}{|c|c|c|c|}
\hline Positive TAB & $16 / 100$ & Visual symptoms & $6 / 16$ \\
\hline Age (years) & $\begin{array}{c}\text { 58-88, Mean } \\
73\end{array}$ & Jaw claudication & $5 / 16$ \\
\hline Female:Male & $13: 3$ & Headache & $\begin{array}{l}11 / \\
16\end{array}$ \\
\hline $\begin{array}{l}\text { GP referral direct to Vascular } \\
\text { Surgery }\end{array}$ & $5 / 16$ & PMR & $1 / 16$ \\
\hline Initial referral to Rheumatology & $4 / 16$ & Other causes of raised ESR & $3 / 16$ \\
\hline Initial referral to Ophthalmology & $4 / 16$ & $\begin{array}{l}\text { Pre-test probability of positive } \\
\text { result }\end{array}$ & $9 / 16$ \\
\hline Initial referral to Neurology & $3 / 16$ & Biopsy influencing treatment & $6 / 7$ \\
\hline Symptom onset to TAB (days) & $\begin{array}{c}\text { 14-90, Mean } \\
52\end{array}$ & & \\
\hline Steroid duration before TAB & $1-28$ days & & \\
\hline Steroid starting dose range & $30-500 \mathrm{mg}$ & & \\
\hline
\end{tabular}

Conclusions: This study has shown that less than a fifth of TAB's conducted during this period at our district general hospital yielded a positive result. There is scope to improve this yield significantly if we identify candidates for TAB better.
There was no positive result for any of the 16 patients less than 58 years of age. The majority had a raised CRP and ESR, though one patient had a CRP of 2 . This reflects the need for vigilance before discounting GCA as a diagnosis.

One patient had a positive TAB even after 28 days of prednisolone $40 \mathrm{mg}$ daily. The majority $(14 / 16)$ had their biopsy within 3 weeks of steroid initiation, indicating that a short delay in biopsy does not rule out a positive result.

This study will help us develop a local pathway including Ophthalmology, Neurology, Vascular Surgery and Primary Care to improve the yield of positive TAB. This will improve patient experience as well as ensure appropriate use of resources.

Disclosure of Interest: None declared

DOI: 10.1136/annrheumdis-2018-eular.4723

\section{AB0685 THE INCIDENCE OF GIANT CELL ARTERITIS IN SLOVENIA - PROSPECTIVE STUDY}

N. Potočnik Puceli ${ }^{1}$, A. Hocevar ${ }^{1}$, R. Ješe ${ }^{1}$, Ž. Rotar ${ }^{1}$, J. Pižem² ${ }^{2}$, M. Hawlina ${ }^{3}$ A. Fakin ${ }^{3}$, M. Tomšič ${ }^{1}{ }^{1}$ Dpt. of Rheumatology, University Medical Center Ljubljana; ${ }^{2}$ Institute of Pathology, Faculty of Medicine, University of Ljubljana; ${ }^{3}$ Department of Ophthalmology, University Medical Center Ljubliana, LJUBLJANA, Slovenia

Background: Giant cell arteritis (GCA) represents the most common vasculitis in adults over age of 50 years in Europe. Recently the diagnostic options greatly improved with the implementation of imaging techniques such as colour Dopple ultrasonography (CDS) and positron emission tomography-computed tomography (PET/CT).

Objectives: The aim of our single centre prospective study was to determine the incidence of GCA in well-defined Slovenian region, based on the temporal artery (TA) biopsy (TAB) and/or the result of CDS and/or PET/CT.

Methods: The study was conducted at University medical centre Ljubljana (UMC Ljubljana), that represents the only secondary/tertiary centre in a region, serving a population of 323297 residents aged 50 years or more (1 76104 females and 147193 males). Patients with suspected GCA are referred either to the Department of Rheumatology, or in case of severe visual disturbances, to the Department of Ophthalmology. In the analysis we included all GCA cases diagnosed between 1 January 2012 and 31 December 2017. The diagnosis of cranial GCA (c-GCA) was established with the help of American College of Rheumatology (ACR) 1990 classification criteria, positive TAB and/or TA CDS. Cases of extracranial large vessel vasculitis (Iv-GCA) were diagnosed using CDS of branches of the aortic arch and/or PET-CT.

Results: During the six-year observation we identified 169 new GCA cases (66.3\% females), with a median (IQR) age of 75.1 (68.6-80.0) years. Forty-two (24.8\%) patients had Iv-GCA, and the others had c-GCA. One-hundred and thirtynine patients (24 lv-GCA and $115 \mathrm{c}-\mathrm{GCA}$ ) fulfilled ACR 1990 classification criteria. The others patients had positive arterial CDS or PET-CT (18 CDS, 9 CDS and PET-CT, 3 PET-CT). TAB was performed in 119 patients and was positive in $88.2 \%$. Clinical characteristics of our GCA cases are presented in table 1 . The estimated annual incidence rate of GCA was 8.7 per 100000 adults aged $\geq 50$ years $(95 \% \mathrm{Cl} 7.5-10.1)$, in C-GCA 6.5 per 100.000 adults aged $\geq 50$ years $(95 \% \mathrm{Cl} 5.5-7.8)$ and in Iv-GCA 2.2 per 100.000 aged $\geq 50$ years $(95 \% \mathrm{Cl} 1.6-$ 2.9).

Abstract AB0685 - Table 1. Characteristics of GCA cohort

\begin{tabular}{|l|l|l|l|}
\hline Characteristics & all GCA & Iv-GCA & c-GCA \\
\hline No. of cases & 169 & 42 & 127 \\
\hline Female gender (\%) & 66.3 & 76.2 & 63.0 \\
\hline Age (years)" & $75.1(68.6-80.0)$ & $69.5(64.4-78.1)$ & $75.7(72.2-81.6)$ \\
\hline Disease duration (day)" & $30(14-60)$ & $60(30-97.5)$ & $28(14-45)$ \\
\hline Constitutional symptoms (\%) & 69.2 & 71.4 & 68.5 \\
\hline Headache (\%) & 71.6 & 45.2 & 80.3 \\
\hline PMR (\%) & 14.2 & 11.9 & 15.0 \\
\hline Jaw claudication (\%) & 45.0 & 26.2 & 51.2 \\
\hline Vision disturbances (\%) & 33.1 & 19.0 & 37.8 \\
\hline Clinically abnormal TA & 62.1 & 38.0 & 69.3 \\
\hline TAB (\%) & $88.2(105 / 119)$ & $79.2(19 / 24)$ & $85.6(89 / 104)$ \\
\hline TA CDS (\%) & $76.9(130 / 160)$ & $54.8(23 / 42)$ & $92.4(109 / 118)$ \\
\hline ESR $\geq 50(m m / h)(\%)$ & 82.8 & 81.0 & 85.0 \\
\hline ACR criteria (\%) & 82.2 & 57.1 & 90.5 \\
\hline
\end{tabular}

Legend: GCA giant cell arteritis; Iv-GCA extracranial large vessel GCA; c-GCA cranial GCA PMR polymyalgia rheumatica; TA temporal artery; ${ }^{\$}$ TA tenderness or decresed pulse; TAB temporal artery biopsy; CDS colour Doppler sonography; ESR erythrocyte sedimentation rate; ACR American Colleague of Rheumatology; ${ }^{*}$ median (interquartile range);

Conclusions: GCA is the most common vasculitis in adults aged 50 years or above, with an annual incidence rate of 8.7 per 100.000 . c-GCA is nearly 3 times more common than IV-GCA.

Disclosure of Interest: None declared

DOI: 10.1136/annrheumdis-2018-eular.2750 